\title{
Laparoscopic Small Bowel Resection of Gastrointestinal Stromal Tumour after Angiographic Diagnosis and Successful Embolization
}

\author{
Marina Garcés Albir ${ }^{1}$, Roberto Martí ${ }^{2}$, Fernando López Mozos ${ }^{2}$, Norberto Cassinello Fernández ${ }^{1}$, \\ Jorge Guijarro Rosaleny ${ }^{3}$, Joaquín Ortega Serrano ${ }^{1}$
}

\footnotetext{
${ }^{1}$ Department of General Surgery, Hospital Clínico Universitario of Valencia, Valencia, Spain; ${ }^{2}$ Department of General Surgery, Esophagogastric Unit, Hospital Clínico Universitario of Valencia, Valencia, Spain; ${ }^{3}$ Department of Radiology, Hospital Clínico Universitario of Valencia, Valencia, Spain.

Email: garalma@hotmail.com
}

Received August 25 ${ }^{\text {th }}$ 2011; revised September 30 ${ }^{\text {th }}, 2011$; accepted October $15^{\text {th }}, 2011$.

\begin{abstract}
Gastrointestinal stromal tumors (GIST) account for 2\% of all tumors of the digestive tract. They are most frequently located in the stomach followed by the small intestine and most often present with mucosal ulceration and erosion associated with gastrointestinal bleeding. Bleeding from the small intestine can be difficult to diagnose and angiography becomes a useful diagnostic and therapeutic procedure in these patients. We present a case of a GIST located in the ileum which presented with a lower gastrointestinal bleeding (LGIB). The patient was stabilized by performing an arteriography and selective embolization of the bleeding point, followed by elective surgery.
\end{abstract}

Keywords: Gastrointestinal Stromal Tumor, Gastrointestinal Blleeding, Angiography, Selective Embolization

\section{Introduction}

Gastrointestinal stromal tumor (GIST) are rare with an incidence ranging between 12 cases - 15 cases per million people [1]. Small bowel GIST represent 2\% of all gastrointestinal tumors and are the second most common neoplasm in the digestive tract [2]. The clinical manifesttations depend on the size and location of the lesion. Gastrointestinal bleeding is the main manifestation of tumors smaller than $3 \mathrm{~cm}-5 \mathrm{~cm}$ [3]. Angiography is considered the best method for diagnosis and initial treatment of gastrointestinal bleeding from the small intestine due to the difficulties of direct access by endoscopy [4].

The gold standard in localized GIST is surgical excision whenever possible. Surgical treatment must achieve complete tumor resection (R0) since this is the most important prognostic factor [5]. Laparoscopic surgery is now considered a valid approach for the treatment of these tumors since criteria for radical resection can also be achieved with this technique. It requires careful intraoperative handling to avoid the rupture of the tumor capsule and the consequent spillage of cells [1].

\section{Case Report}

A 49 year old woman with no previous medical history was admitted in our hospital with lower gastrointestinal bleeding. Physical examination revealed mucocutaneous pallor, tachycardia and hypotension. Abdominal examination was unremarkable and laboratory findings showed a haemoglobin level of $7.8 \mathrm{~g} / \mathrm{dL}$.

Gastroscopy was normal and colonoscopy reported a gastrointestinal bleeding from the small intestine. An abdominal CT scan was then performed revealing a 3 - 4 $\mathrm{cm}$ lesion in the ileum wall without active leak of contrast agent (Figure 1). The working diagnosis was a lower gastrointestinal bleed from the small intestine. The patient was transfused $1200 \mathrm{ml}$ of packed red cells and transferred to our hospital for emergency arteriography. After selective catheterization of the superior mesenteric artery a vascular tangle with active leak of contrast agent into the ileum lumen was detected and superselective foam-embolization was successfully performed (Figure 2(a)-(c)). Surgery was programmed for 24 hours later after bleeding was stopped. 


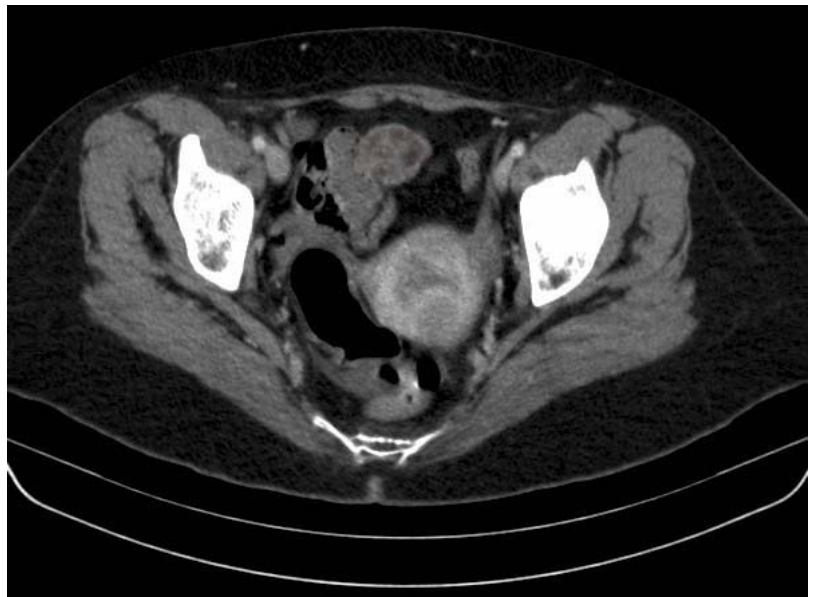

Figure 1. Abdominal-pelvic scan with intravenous contrast. Mass is seen approximately $4 \mathrm{~cm}$ in diameter attached to ileum.

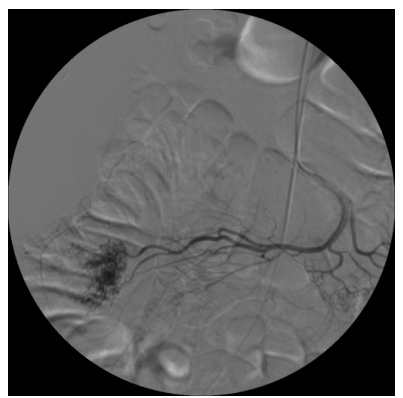

(a)

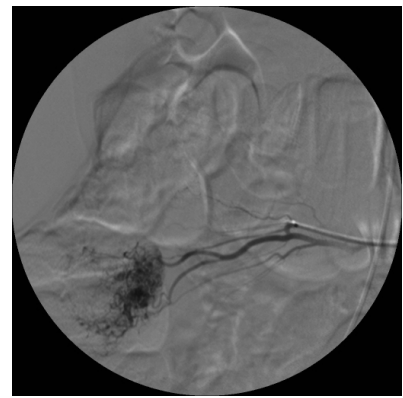

(b)

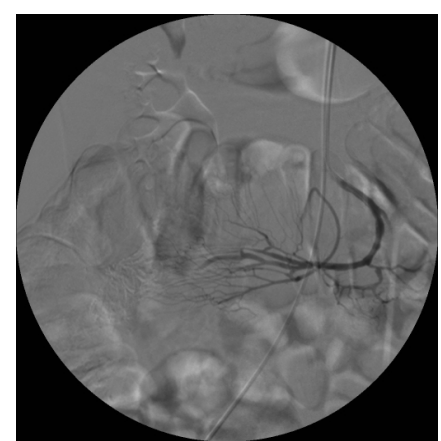

(c)

Figure 2. Arteriography. (a) and (b): Selective catheterization of the superior mesenteric artery showed ileum branches corresponding to the previously localized tumor in the CT scan; (c): image after embolization.

\subsection{Surgical Technique}

General anaesthesia was used and the patient was placed in the supine position with the legs spread apart (French position) and $20^{\circ}$ reverse Trendelenburg. The surgeon stood between the legs and the first assistant on the left hand side of the patient. Pneumoperitoneum was estab- lished by an infra-umbilical open technique. Two more ports were placed in the right $(10 \mathrm{~mm}-12 \mathrm{~mm})$ and left iliac quadrants (5 mm).

A small bowel resection was performed with careful handling to avoid tumor capsule rupture. The resected specimen of ileum which included the tumor was approximately $5 \mathrm{~cm}$ in length. A side to side isoperistaltic intracorporeal anastomosis was performed using a linear $60 \mathrm{~mm}$ stapler (ENDO GIA ${ }^{\circledR}$ Autosuture, Norwalk, CT) with an absorbable running suture to close the enterotomy. The specimen was extracted through the infra-umbilical port incision which was protected by a plastic-bag (Figure 3).

Operative time was 95 minutes and neither intraoperative nor postoperative transfusion was required. The patient was uneventfully discharged 4 days after surgery. Patient remains disease free at 15 month follow-up.

\subsection{Histological Study}

The histopathological study revealed a $3 \mathrm{~cm}$ diameter polypoid lesion without mucosal involvement. Microscopic findings showed a proliferation of monomorphic atypical spindle cells, with poorly defined cytoplasm, eosinophilic oval nucleus and nucleolus, focally evident fine chromatin, which are arranged in bundles in different directions. Resection margins were free of tumour infiltration. Tumour cells had a low proliferative index (Ki67 < 10\%), with 1 mitosis per 50 high-power field (HPF). Immunohistochemistry showed positivity for C-Kit, CD34, SMA, vimentin, p53, MDM2, CD99, PGP 9'5, PDGRF-alpha and chromogranin. The tumor was classified as low risk according to the Miettinen classifycation.

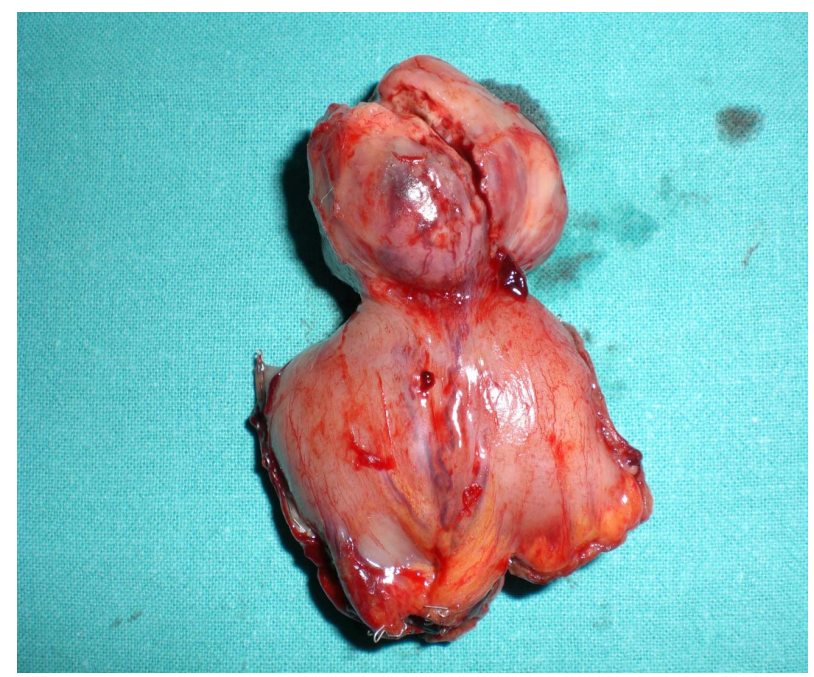

Figure 3. The specimen was broken during the extraction, when it was in the plastic bag. 


\section{Discussion}

The clinical manifestations of GIST depend on their size and location. Gastrointestinal tract bleeding is the most common presentation (50\%), followed by abdominal pain $(20 \%-40 \%)$ and obstruction (20\%). One third of them remain asymptomatic and are an incidental finding [2,6]. GI bleeding can be acute (melena, haematemesis or haemaotochezia) or chronic (anemia, fecal occult blood) and is caused by mucosal erosion.

Diagnosis of GIST depends on their location. For the upper gastrointestinal tract (oesophagus, stomach or duodenum) the method of choice is endoscopic ultrasonography (EUS) \pm biopsy (EUS-FNA) [7]. Wherever location is not accessible to endoscopy diagnosis can be made by CT scan, MRI or capsule enteroscopy [5]. In our case the diagnosis was confirmed by CT, because the location of the lesion was not accessible to gastroscopy and colonoscopy. CT could only detect a tumour located in the small bowel. For lower gastrointestinal bleeding, angiography is the method of choice for both diagnostic and therapeutic purposes. Transcatheter embolization has a success rate of $70 \%$ - $90 \%$ without ischemic complications $[4,8]$. This can be explained by the rich vascular supply of the small bowel. Recurrent haemorrhage occurs in less than $15 \%$ of cases [8]. It has also been used to reduce tumor size in selected cases with one located in the duodenum, a $40 \%$ reduction in tumor volume 14 days after embolization allowing a more limited resection, although this practice is not standardized [9]. In this case, arteriography with superselective embolization located the exact tumour site and complete resolution of GI bleeding. In addition, the patient was haemodinamically stabilized and blood loss replaced before surgery.

Surgical resection is considered the treatment of choice in localized GIST.

An exception could be made in those tumours located in the esophagogastric junction or in the duodenum, less than $2 \mathrm{~cm}$ in size, where control and follow-up can be performed through endoscopic ultrasonography [10]. Laparoscopic resection has been shown to be safe and effective in treating gastric and small intestine GIST, offering the advantages of minimally invasive surgery without the disadvantages of local recurrence. The laparoscopic approach to GIST is currently recommended only in high volume centres with high experience in advanced laparoscopic procedures. Results published in recent years show large series of successful resection for gastric GIST through a minimally invasive access [11, 12]. Hence laparoscopic approach has shown good results in terms of free resection margins and long time survival with no significant tumour implants described in port sites. Most authors consider that a laparoscopic wedge resection can be safely performed if the tumor size is $5 \mathrm{~cm}$ or less [13-16]. For GIST larger than $5 \mathrm{~cm}$ handassisted laparoscopic port is advisable. There is little information on laparoscopy GIST resection in other locations such as the colon, duodenum or small bowel, however laparoscopic surgical principles in these cases must be similar to those tumours in different locations. Tumor removal must be performed through a protective plastic bag in all cases to minimize the risk of port-site recurrence [10,13-16].

Special attention must be paid to avoid tumor rupture either spontaneously or during manipulation, which is associated with a higher risk of peritoneal spread and a worse prognosis [17]. If this occurs, we recommend extensive peritoneal lavage and careful search for tumour fragments [18]. It is difficult to determine whether this situation should be considered as metastatic disease.

Imatinib is currently approved for use as neoadjuvant therapy in patients where R0 resection does not seem feasible due to locoregional involvement and when an extended resection is not recommended [1]. Usually, the maximum response to treatment occurs within $6-12$ months after which surgery can usually be performed.

The preoperative role of tumor embolization of active bleeding or for tumor shrinkage is unknown.

\section{Conclusions}

This case showed GIST can be safely resected through a minimally invasive approach, even in complicated presentations such as lower gastrointestinal bleeding. Angiographies studies can be helpful as a first step in manages of these tumors and complications. This could ensure better conditions for a subsequent laparoscopic resection.

\section{REFERENCES}

[1] P. G. Casali, L. Jost, P. Reichardt, M. Schlemmer and J. Y. Blay, "Gastrointestinal Stromal Tumours: ESMO Clinical Recomendations for Diagnosis, Treatment and Follow-Up," Annals of Oncology, Vol. 20, No. 4, 2009, pp. 64-67. doi:10.1093/annonc/mdp131

[2] M. Miettinen, M. Majidi and J. Lasota, "Pathology and Diagnostic Criteria of Gastrointestinal Stromal Tumors (GISTs): A Review,” European Journal of Cancer, Vol. 38, Suppl. 5, 2002, pp. 39-51. doi:10.1016/S0959-8049(02)80602-5

[3] A. Poveda, V. Artigas, A. Casado, J. Cervera , X. García Del Muro, J. Antonio López-Guerrero, A. López-Pousa, J. Maurel, L. Ortega, R. Ramos, I. Romero, M. J. Safont and J. Martín, "Clinical Practice Guidelines in Gastrointestinal Stromal Tumours (GEIS): Update 2008,” Cirugia Espanola, Vol. 84, Suppl. 1, 2008, pp. 1-21. 
[4] J. J. Farrell and L. S. Friedman, "Review Article: The Management of Lower Gastrointestinal Bleeding," Alimentary Pharmacology \& Therapeutics, Vol. 21, No. 11, 2005, pp. 1281-1298. doi:10.1111/j.1365-2036.2005.02485.x

[5] G. Demetri, R. Benjamin, C. D. Blanke, J. Y. Blay, P. Casali, H. Choi, C. L. Corless, M. Debiec-Rychter, R. P. DeMatteo, D. S. Ettinger, G. A. Fisher, C. D. Fletcher, A. Gronchi, P. Hohenberger, M. Hughes, H. Joensuu, I. Judson, A. Le Cesne, R. G. Maki, M. Morse, A. S. Pappo, P. W. Pisters, C. P. Raut, P. Reichardt, D. S. Tyler, A. D. Van den Abbeele, M. von Mehren, J. D. Wayne, J. Zalcberg, et al., "NCCN Task Force Report: Optimal Management of Patients with Gastrointestinal Stomal Tumors (GIST) - Update of the NCCN Clinical Practice Guidelines," Journal of the National Comprehensive Cancer Network, Vol. 2, Suppl. 2, 2007, pp. 1-29.

[6] M. Miettinen and J. Lasota, "Gastrointestinal Stromal Tumors. Review on Morphology, Molecular Pathology, Prognosis, and Differential Diagnosis," Archives Pathology \& laboratory Medicine, Vol. 130, No. 10, 2003, pp. 1466-1476.

[7] S. Lau, C. K. Tam, C. K. Kam, C. Y. Lui, C. W. Siu, H. S. Lam and K. L. Mak, "Imaging of Gastrointestinal Stromal Tumor (GIST),” Clinical Radiology, Vol. 59, No. 6, 2004, pp. 487-498. doi:10.1016/j.crad.2003.10.018

[8] J. Barnert and H. Messmann, "Diagnosis and Management of Lower Gastrointestinal Bleeding," Nature Reviews Gastroenterology Hepatology, Vol. 6, 2009, pp. 637-646. doi:10.1038/nrgastro.2009.167

[9] N. Kurihara, K. Kikuchi, N. Kurihara, K. Kikuchi, M. Tanabe, Y. Kumamoto, A. Tsuyuki, Y. Fujishiro, Y. Otani, T. Kubota, K. Kumai and M. Kitajima, "Parcial Resection of the Second Portion of the Duodenum for Gastrointestinal Stromal Tumor after Effective Transarterial Embolization,” International Journal of Clinical Oncology, Vol. 10, No. 6, 2005, pp. 433-437. doi:10.1007/s10147-005-0503-Z

[10] Y. Otani, T. Furukawa, M. Yoshida, Y. Saikawa, N. Wada, M. Ueda, T. Kubota, M. Mukai, K. Kameyama, Y. Sugino, K. Kumai and M. Kitajima, "Operative Indications for Relatively Small (2 - $5 \mathrm{~cm}$ ) Gastrointestinal Stromal Tumors of the Stomach Based on Analysis of 60 Operated Cases,” Surgery, Vol. 139, No. 4, 2006, pp. 484-

\section{2. doi:10.1016/j.surg.2005.08.011}

[11] K. L. Huguet, R. M. Rush Jr, D. J. Tessier, R. T. Schlinkert, R. A. Hinder, G. G. Grinberg, M. L. Kendrick and K. L. Harold, "Laparoscopic Gastric Gastrointestinal Stromal Tumor Resection: The Mayo Clinic Experience," Achives of Surgery, Vol. 143, No. 6, 2008, pp. 587-590. doi:10.1001/archsurg.143.6.587

[12] F. Catena, M. Di Battista, P. Fusaroli, L. Ansaloni, V. Di Scioscio, D. Santini, M. Pantaleo, G. Biasco, G. Caletti and A. Pinna, "Laparoscopic Treatment of Gastric GIST: Report of 21 Cases and Literature's Review,” Journal of Gastrointestinal Surgery, Vol. 12, No. 3, 2008, pp. 561568. doi:10.1007/s11605-007-0416-4

[13] E. I. Bedar, J. Mamazza, C. M. Schlachta and E. C. Poulin, "Laparoscopic Resection of Gastrointestinal Stromal Tumors: Not All Tumors are Created Equal,” Surgical Endoscopy, Vol. 20, No. 3, 2006, pp. 500-503.

[14] R. Beriduague, E. M. Targarona, X. Feliu, V. Artigas, C. Balagué, A. Aldeano, A. Lahoud, J. Navines, E. Fernandez-Sallent and M. Trias, "Laparoscopic Resection of Clinically Suspected Gastric Stromal Tumors,” Surgical Innovation, Vol. 13, No. 4, 2007, pp. 231-237. doi:10.1177/1553350606295960

[15] Y. W. Novitsty, K. W. Kercher, R. F. Sing and B. T. Heniford, "Long-Term Outcomes of Laparoscopic Resection of Gastric Gastrointestinal Stromal Tumors," Annals of Surgery, Vol. 243, No. 6, 2006, pp. 738-745. doi:10.1097/01.sla.0000219739.11758.27

[16] M. Iwahashi, K. Takifuji, T. Ojima, M. Nakamura, M. Nakamori, Y. Nakatani, K. Ueda, K. Ishida, T. Naka, K. Ono and H. Yamaue, "Surgical Management of Small Gastrointestinal Stromal Tumors of the Stomac," World Journal of Surgery, Vol. 30, No. 1, 2006, pp. 28-35. doi:10.1007/s00268-005-7944-4

[17] C. D. Blanke, B. L. Eisenberg and M. C. Heinrich, "Gastrointestinal Stromal Tumors," Current Treatmant Options in Oncology, Vol. 2, No. 6, 2001, pp. 61-65.

[18] R. P. DeMatteo, J. J. Lewis, D. Leung, S. S. Mudan, J. M. Woodruff and M. F. Brennan, "Two Hundred Gastrointestinal Stromal Tumors: Recurrence Patterns and Prognosis Factors for Survival,” Annals of Surgery, Vol. 231, No. 1, 2000, pp. 51-58. doi:10.1097/00000658-200001000-00008 